\title{
MULTIPLICATIVE DERIVATIVE AND ITS BASIC PROPERTIES ON TIME SCALES
}

\author{
Sertac Goktas ${ }^{1}$, Emrah Yilmaz ${ }^{2}$, and Ayşe YAR ${ }^{2}$ \\ ${ }^{1}$ Mersin Universitesi \\ ${ }^{2}$ Firat University
}

March 17, 2021

\begin{abstract}
We define multiplicative derivative and its properties on time scales. Then, we restate many concepts for multiplicative analysis such as derivative, Rolle's theorem, mean value theorem and increasing decreasing property on time scales. We aim to create important fields of study by carrying this most important issue of multiplicative analysis, which has applications in economics, finance and many other fields, to time scale calculus
\end{abstract}

\section{Hosted file}

multiclative time scales.pdf available at https://authorea.com/users/402132/articles/514012multiplicative-derivative-and-its-basic-properties-on-time-scales 